\title{
Interoperability framework for integrated e-health services
}

\author{
M. Miftakul Amin'1, Adi Sutrisman², Deris Stiawan $^{3}$, Ermatita $^{4}$, Mohammed Y. Alzahrani $^{5}$, \\ Rahmat Budiarto ${ }^{6}$ \\ ${ }^{1,2}$ Department of Computer Engineering, Politeknik Negeri Sriwijaya, Indonesia \\ ${ }^{3,4}$ Department of Computer Science, Universitas Sriwijaya, Indonesia \\ ${ }^{5,6}$ College of Computer Science and IT, Albaha University, Saudi Arabia
}

\begin{tabular}{|c|c|}
\hline Article Info & ABSTRACT \\
\hline Article history: & As one of the country with largest population in the world, Indonesia \\
\hline Received Aug 26, 2019 & $\begin{array}{l}\text { is facing major challenge to serve people in various sectors, one of them } \\
\text { is health sector. Utilization of Information and Communication Technology }\end{array}$ \\
\hline Revised Oct 31, 2019 & (ICT) has a strategic role in improving efficiency and expanding services \\
\hline Accepted Nov 24, 2019 & $\begin{array}{l}\text { access. The main challenge related to data interoperability is the ability } \\
\text { to integrate and synchronize data sourced from health information (e-health) }\end{array}$ \\
\hline Keywords: & a framework to materialize data interoperability and information exchange \\
\hline E-health system & among e-health systems. The interoperability is materialized by utilizing \\
\hline Interoperability & Service technology. Service oriented analysis and design (SOAD) is used \\
\hline SOA & as method in the system development at the analysis phase and designing \\
\hline SOAD & phase to generate service portfolio which consisting of three \\
\hline Web service & $\begin{array}{l}\text { levels: conceptual view, logical view, and physical view. This research } \\
\text { intruduces Interoperability Matrix (IM) to describe the modules and entities } \\
\text { that involved in the framework design. The framework resulted from this } \\
\text { research can be used as reference in e-health systems development in variety } \\
\text { of health care applications. }\end{array}$ \\
\hline
\end{tabular}

This is an open access article under the CC BY-SA license.

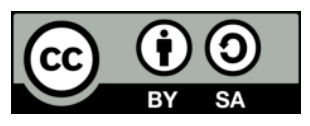

Corresponding Author:

Deris Stiawan,

Department of ComputerEngineering,

Universitas Sriwijaya,

Jalan Srijaya Negara Bukit Besar, Palembang 30139, Indonesia.

Email: deris@unsri.ac.id

\section{INTRODUCTION}

At this moment, Indonesia is in the fourth rank, as one of the largest population country in the world. The role of development sector of Information and Communication Technology (ICT) in Indonesia has been widely perceived by society. In the health sector, application of ICT is known as health information systems (e-health). The decree of the Minister of Health of the Republic of Indonesia, number: 192/MENKES/SK/VI/2012 mentions that e-health system is the use of ICT in health sector, especially to improve health service. Implementation and application of e-health in Indonesia has started since 1985 [1], and over time also adapt to the development of ICT which is most of directed to the aspect of health care service. On the other hand, we come to the era of high-speed technology, characterized by cellular technology, high-speed Internet, and wireless communication [2]. This technology encourages the development of e-health in adopting the development of the technology. Ministry of Health of the Republic of Indonesia in 2004 defines the National Health System (SKN) as a setting that compils the efforts of Indonesian integrated and mutually supportive, to ensure the supermacy of health as 
manifestation of general welfare as intended in the opening of In donesia constitution (UUD 1945). In order to keep this health system on target, the management of population database is also one of the aspect that need to be considered. The Ministry of Interior of the Republic of Indonesia has implemented E-KTP, with Citizen Identification Number (NIK) as single reference in population administration [3]. This E-KTP Data as the referral for various services for the society, including in the health sector [4].

In e-health sytem development, wide range of healthcare applications are built by various vendors and run on different platforms. One of the challenge in the context of app development is interoperability, which plays an important role in data and information exchange [5]. As time goes by, healthcare applications begin to shift from paper-based to paper-less with the use of computer. Healthcare organization such as hospital requires relevant data and necessary information in its e-health such as population data, health insurance data, and electronic medical records. Many countries have been actively engaged in development of interoperability for data exchange and electronic transaction a mong government agencies to provide better public service to its citizen [6]. In e-health system, data associated with the patient is stored in distributed data source [7], which is in organization of health providers such as doctor, hospital, laboratory, and other. These health providers are autonomous, so that data is independently managed by the organization. Therefore, when data will be exchanged between organizations, each organization has agreed to share data with considering objectives, schemes, and agreed data [8].

Interoperability generally is defined as ability of two or more systems or components to exchange information and used the exchange information [9]. Data exchange and information format play an important role in facilitating interoperability. Standardization of data exchange and information format is very important to do [10]. Interoperability allows different information systems and organizations to work together. Interoperability have four levels as shown in Figure 1. The development of data interoperability requires an interface, which is published following specific standard. A system, which does not require the ability of exchange data and information, does not require such interface [12]. Referring to Figure 1, the organizational interoperability level allows performing both internal and external interoperability. Internal interoperability can occur in some data/information sources from an organization, while external interoperability allows the exchange of data perfom by different organizations.

\begin{tabular}{|c|c|}
\hline $\begin{array}{c}\text { Organizational } \\
\text { Interoperability }\end{array}$ & $\begin{array}{c}\text { Business process integration beyond the } \\
\text { boundaries of a single organization }\end{array}$ \\
\hline $\begin{array}{c}\text { Semantic } \\
\text { Interoperability }\end{array}$ & $\begin{array}{c}\text { Ensuring the same meaning of exchanged } \\
\text { data through predefined and shared } \\
\text { meaning of terms and expressions }\end{array}$ \\
\hline $\begin{array}{c}\text { Syntactic } \\
\text { Exchange of information through } \\
\text { predefined data format and structure }\end{array}$ \\
\hline $\begin{array}{c}\text { Technical } \\
\text { Interoperability }\end{array}$ & $\begin{array}{c}\text { Technical end-to-end exchange of data } \\
\text { among systems }\end{array}$ \\
\hline
\end{tabular}

Figure 1. Levels of Interoperability (adapted from [11])

In e-health systems, interoperability is required in process of exchanging data related to patient [13]. In its implementation, minimal interoperability involves two different systems or applications. One application or system serves as data provider, while other applications/systems act as data consumer. Referring to Figure 1, the syntactic interoperability level allows multiple applications that built using different type of programming languages and running on variety of platform can exchange data and information. While the syntactic interoperability level focuses on data exchange mechanism, and at semantic interoperability level, it allows a document to be translated and read on receiver data/information side.

Interoperability can be implemented using Service Oriented Architecture (SOA) approach. SOA is one of the approach to meet the standards of need and quality of software development. SOA cover functionality of a system into services [14]. Then, various applications with different platforms can connect each other and exchange data without having direct connection each other (loosely coupled). SOA is a form of architectural technology, which follows the principles of service orientation [15] by performing app roach through dividing large functionality into smaller services with specific objective. Many of that technology can be used to implement SOA architecture, including CORBA (Common Object Request Broker Architecture), DCOM (Distributed Component Object Model), RMI (Remote Method Invocation), and Web Services. Some of these technologies in another side have weakness, for example CORBA, DCOM, RMI is closed (proprietary) so that the development is only on certain platform. While the Web service is open (non-proprietary) and web-based. 
The Web service is a communication method between two electronic devices running on computer network [16]. The service, which is owned, by web service is software module provided by service provider [17]. Web Service is based on the concept of SOA, as an alternative solution in development of distributed system. At the beginning of web service development, people use SOAP protocol, until REST protocol was introduced $[18,19]$. Figure 2 provides information on the differences between SOAP and REST protocol. Figure 2(a) shows that the SOAP Protocol defines web services as three entities, which are service provider, service registry, and service consumer. Service provider serves the requests of service consumer. While the service consumer in general is an application that consumes web services. Service registry acts as directory, provides number of services, in which there is description of the service provided. Based on the description and documentation provided by this service registry, service consumer can find a service and interact with the service provider. Communication between each entity uses XML notation.

Fielding [20] introduced representational State Transfer (REST) protocol as shown in Figure 2(b) Fielding defines REST as a client/server communication where the client requests to the server, and the server sends response to the client. Communication between this client/server is based on the resource which identified as a URI. RESTful Web Services use HTTP methods such as GET, PUT, POST, and DELETE which can be integrated with CRUD operation (Create, Read, Update, and DELETE) in a database operation [21]. In every software engineering methodology, there are steps, which must be followed for system analysis and design. In the development of Service Oriented Architecture (SOA), developers use an approach called Service Oriented Analysis and Design (SOAD), which provides guidance on design implementation of SOA concept through three stages, including Conceptual View (CV), Logical View (LV), and Physical View (PV) [22]. The results of these three steps will be packaged into a service portfolio [23].

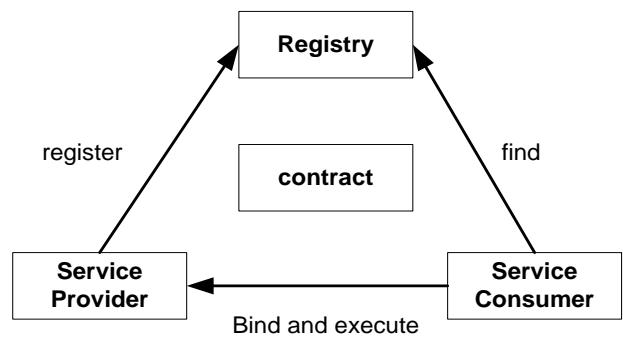

(a)

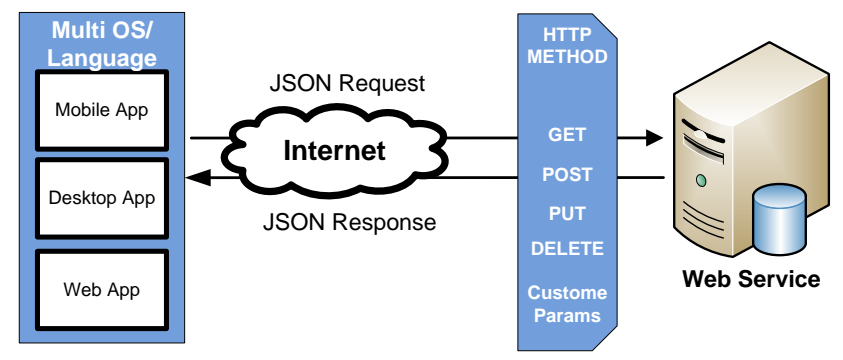

(b)

Figure 2. SOAP and REST protocol, (a) SOAP protocol (adapted from [19]), (b) REST protocol (adapted from [3])

Currently, organization in public service in global business environment are challenged by very competitive and rapid changes that demands cooperation between organizations. This challenge leads to software implementation needs, which have high level of interoperability and require cross-organization business process modeling [24]. Business processes is a series of task and activity executed to produce specific output. Intra-organizational business process is a series of activities carried out by a scope of organization, while the carried out cross-organizational business process activity is not only within one organization, but engage with other organizations to achieve common objectives. Business processes need to be documented, optimized, and possible to do business process automation (BPA). Most of the cross-organizational business processes are implemented using an infrastructure such as Web Services [25].

\section{RESEARCH METHOD}

This work follows SOAD Framework as logical approach for classification and organize information related to the analysis and SOA concept design. This system development step will result portfolio service as information stored for service consolidation. Figure 3 depicts the proposed Service Portfolio.

Steps in CV consist of functional domains, business processes, business services, software services and software components. The CV also illustrates business process activity diagram (BPAD) and subbusiness process activity diagram (SBPAD), which illustrates series of activities in each business process. In LV, the Steps are based on Enterprise Architecture (EA) which is useful for mapping the structure and objectives 


\subsection{Architechtural design}

This research work aims to come out with a model of interoperability mechanism for exchanging data and information among several database namely: National Population Database, health insurance database, e-health operated by a health data provider such a s hospital. The design of interoperability scena rio is presented in Figure 5. Stakeholders in turn, are able to develop applications with different programming languages and platforms. National Population Database and health insurance system can be accessed by providing interfaces in collection of Web services, so that the e-health system can access the data that have been provided.

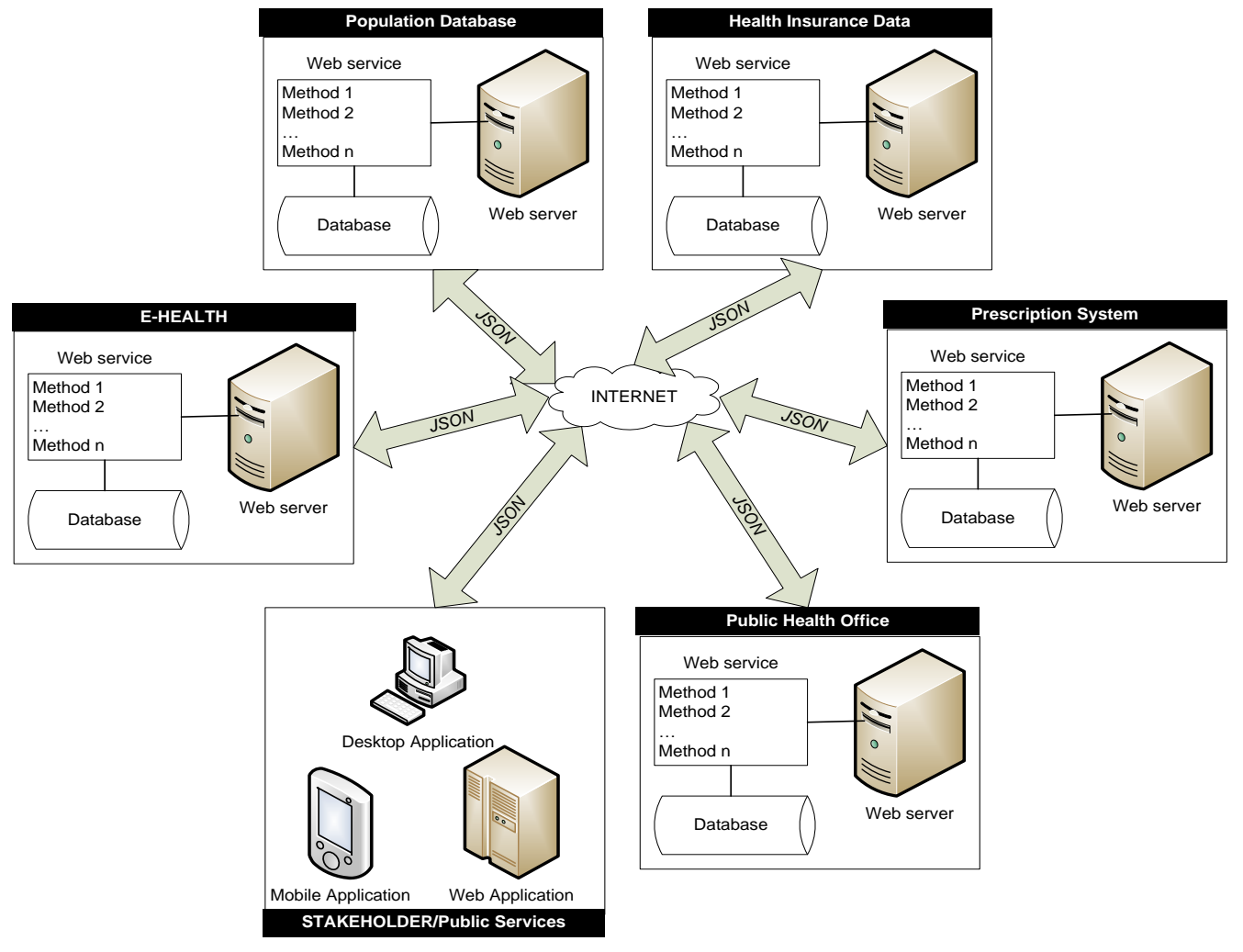

Figure 5. Interoperability of e-health system scenario

\subsection{Business process modelling of RESTful web service data exchange}

Figure 6 shows a series of business process activities that show the parties who involved in the e-health service interoperability framework. E-health system is the center of health care activities. The e-health system is an application used by hospital, public health center, and health clinic. The Framework is built using RESTful Web service which involving multiple entities including national population data, health insurance data, electronic prescription system, and health service. Furthermore, the already formed framework can be accessed by stakeholders as open system architecture for software developers.

The framework that will be built require connections to RESTful Web Service with predefined mechanism. Once authentication process is received, the dataset which presented by RESTful Web service can be accessed. The Data provided by RESTful Web Service can be accessed by accessing number of services. The number is provided in the routing mechanism in the form of resource address list (URI). To execute URI the HTTP protocol is used and the method is in the form of POST, PUT, GET, and DELETE.

Dataset that is generated both from and to the RESTful Web Service Framework will perform parsing JSON data structure and adjusted by the variable name and data type owned by the software or application that used by e-health System. The process of adjusting variable name and data type used by the e-health system and RESTful Web Service is known as Schema Mapping. This schema can be recognized, because the key-value, which pair in JSON will be adjusted at application level and also at database level. 


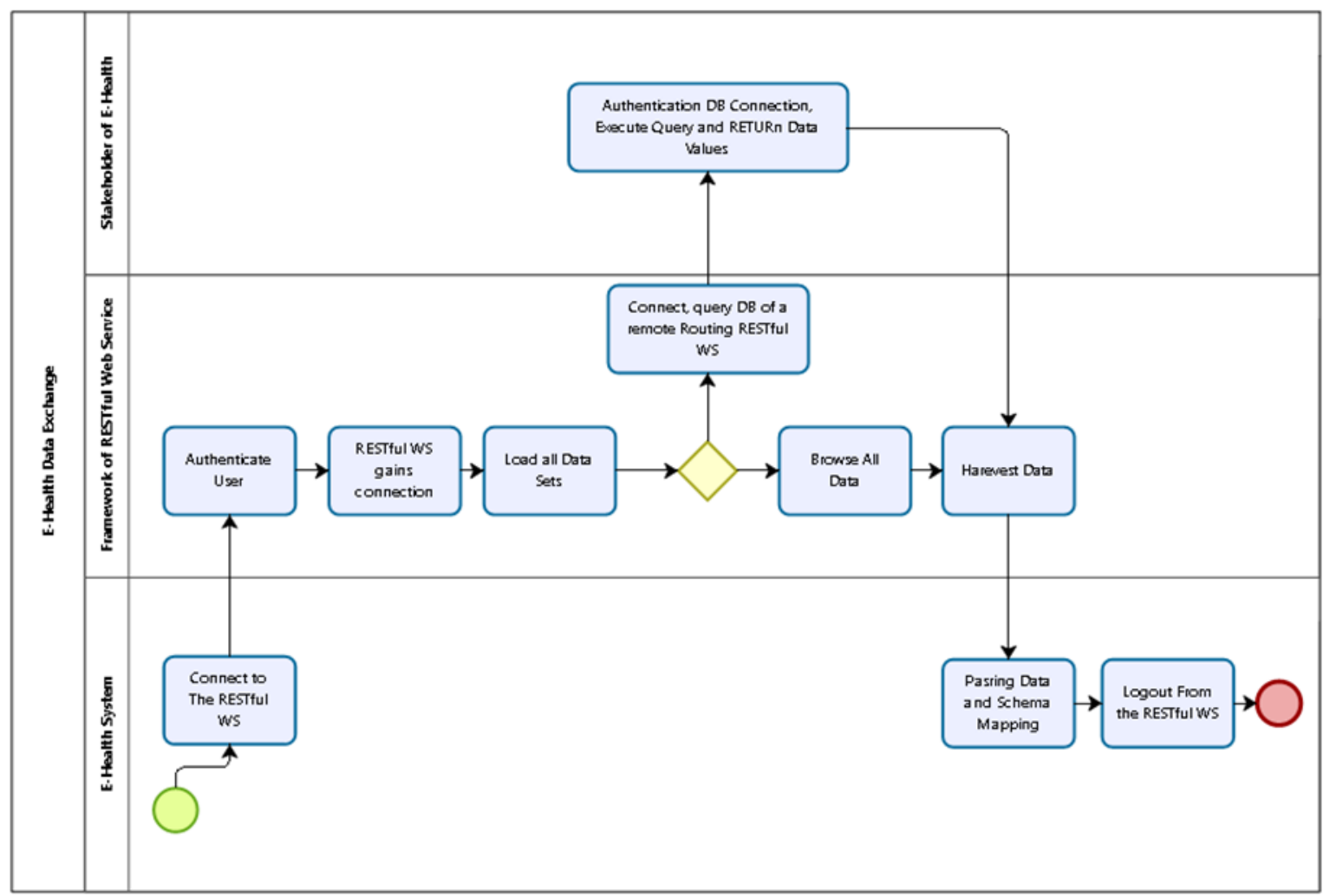

Figure 6. Data exchange of RESTful web service

\subsection{Interoperability matrix}

In the development of framework interoperability which integrated several entities or modules which involved in the system can be described in an interoperability matrix (IM) diagram. This Diagram can provide entity information or module which serves as service provider and which serves as consumer of the service which has been provided (consumer). Interoperability Matrix (IM) Dia gram can be presented in Figure 7. Reffering to Figure 6, interoperability development of e-health service can be described in the form of Interoperability Matrix (IM), describing consumer/provider between entities involved in the framework. Consumer is an entity, which requires data by executing service provided by a provider. Data exchange interoperability requirements can be seen in Table 1.

\begin{tabular}{|c|c|c|c|c|c|}
\hline & E-Health & $\begin{array}{l}\text { National } \\
\text { Population } \\
\text { Database }\end{array}$ & $\begin{array}{l}\text { Health } \\
\text { Insurance } \\
\text { Data }\end{array}$ & $\begin{array}{l}\text { Prescription } \\
\text { System }\end{array}$ & $\begin{array}{c}\text { Public Health } \\
\text { Office }\end{array}$ \\
\hline E-Health & & $\begin{array}{c}\text { Consume } \\
\text { Patient } \\
\text { Profile }\end{array}$ & $\begin{array}{l}\text { Consume } \\
\text { Services } \\
\text { Insurance }\end{array}$ & $\begin{array}{c}\text { Provide } \\
\text { Prescription } \\
\text { Data }\end{array}$ & $\begin{array}{c}\text { Provide } \\
\text { Report } \\
\text { Health Data }\end{array}$ \\
\hline $\begin{array}{l}\text { National } \\
\text { Population } \\
\text { Database }\end{array}$ & $\begin{array}{l}\text { Provide } \\
\text { Patient } \\
\text { Profile }\end{array}$ & & $\begin{array}{l}\text { Provide } \\
\text { Patient } \\
\text { Profile }\end{array}$ & $\begin{array}{l}\text { Provide } \\
\text { Patient } \\
\text { Profile }\end{array}$ & \\
\hline $\begin{array}{l}\text { Health } \\
\text { Insurance } \\
\text { Data }\end{array}$ & $\begin{array}{c}\text { Provide } \\
\text { Services } \\
\text { Insurance }\end{array}$ & $\begin{array}{c}\text { Consume } \\
\text { Patient } \\
\text { Profile }\end{array}$ & & $\begin{array}{c}\text { Provide } \\
\text { Insurance } \\
\text { Services }\end{array}$ & \\
\hline $\begin{array}{l}\text { Prescription } \\
\text { System }\end{array}$ & $\begin{array}{l}\text { Consume } \\
\text { Prescription } \\
\text { Data }\end{array}$ & $\begin{array}{c}\text { Consume } \\
\text { Patient } \\
\text { Profile }\end{array}$ & $\begin{array}{c}\text { Consume } \\
\text { Insurance } \\
\text { Services }\end{array}$ & & \\
\hline $\begin{array}{c}\text { Public Health } \\
\text { Office }\end{array}$ & $\begin{array}{l}\text { Consume } \\
\text { Report } \\
\text { Health Data }\end{array}$ & & & & \\
\hline
\end{tabular}

Figure 7. Interoperability matrix 


\begin{tabular}{|c|c|c|}
\hline From & To & Services \\
\hline 1. E-health & $\begin{array}{c}\text { National population } \\
\text { database }\end{array}$ & $\begin{array}{l}\text { Health information system which on health institution needs national population } \\
\text { data which use as single identity for patient profile. E-health role as entity which } \\
\text { ask for service (consumer) while National Population Database act as provider. }\end{array}$ \\
\hline 2. E-health & Health insurance data & $\begin{array}{l}\text { E-health needs insurance service accepted by patient when comes to health } \\
\text { institution. In this context e-health acts as consumer while health insurance data } \\
\text { acts as provider }\end{array}$ \\
\hline 3. E-health & Prescription system & $\begin{array}{l}\text { Every prescription system's service can create a system which generates its data } \\
\text { by e-health. Prescription system becomes electronic refference for prescription } \\
\text { by doctor to patient, so this information can be accessed openly for stakeholder } \\
\text { who needs information of medicine prescription. In this scenario, e- health acts } \\
\text { as provider and prescription system acts as consumer. }\end{array}$ \\
\hline 4. E-health & Public health office & $\begin{array}{l}\text { Healthcare data is reported periodically to the head of health office. Those data } \\
\text { are result of operational health service exists in every health institution. In th is } \\
\text { scenario e-health acts as provider and public Health Office acts as consumer }\end{array}$ \\
\hline $\begin{array}{l}\text { 5. National } \\
\text { population } \\
\text { database }\end{array}$ & Prescription system & $\begin{array}{l}\text { Refference of National Population Database is used as single identity in } \\
\text { prescription system. In this scenario the National Population Database acts as } \\
\text { provider, while prescription system acts as consumer. }\end{array}$ \\
\hline 6. National & & Single identity of National Population Database is used as patientrefference who \\
\hline $\begin{array}{l}\text { population } \\
\text { database }\end{array}$ & Insurance system & $\begin{array}{l}\text { has right to get health service insurance. In this scenario, Nation al Pop ulation } \\
\text { Database role is as provider, while insurance system role is as consumer. }\end{array}$ \\
\hline $\begin{array}{l}\text { 7. Prescription } \\
\text { system }\end{array}$ & Insurance system & $\begin{array}{l}\text { Patien medicine prescription system needs information type of medicine covered } \\
\text { by health insurance. So, in this scenario ins urance system acts as provider, while } \\
\text { prescription system acts as consumer }\end{array}$ \\
\hline
\end{tabular}

\section{CONCLUSION}

This work has resulted a design of framework for interoperability of several e-health services. The SOAD approach is used as system development method which specifies the system in the form of a portfolio consisting of conceptual view, logical view, and physical view. Furthermore, this work described relation between system and integrated entities, and data and information exchange in a form of Interoperability matrix (IM), so the entities/systems, which serve as consumer or provider are clearly identified and can be used as a reference for system development in e-health application domain. In interoperability framework, which has been designed, data exchange between applications can be done using neutral data format such as JSON. The data format can be parsed and adjusted using variable and the data type implemented by software application connected in the framework. The authors plan to conduct a further research work through experimenting development of e-health system using multi-platforms environment including console-based, desktop, mobile, and web.

\section{ACKNOWLEDGEMENTS}

The author thanked to all the parties who had given support so that this publication was published. Thanks to the Ministry of Research, Technology, and higher education who have funded this research on the Intercollegiate Cooperation Research Scheme (PKPT) year of funding from 2018 to 2019.

\section{REFERENCES}

[1] Nugraha D. C. A. and Aknuranda I, "An overview of e-health in indonesia: past and present applications," International Journal of Electrical and Computer Engineering (IJECE), vol. 7, no. 5, pp. 2241-2450, 2017.

[2] Zaman S. B., Hossain N., Ahammed S., Ahmed Z., "Contexts and opportunities of e-health tehnology in medical care," Journal of Medical Research and Innovation, vol. 1, no. 2, pp. 1-4, 2017.

[3] Kinanti P. S., "Policy implementation of electronic Identity Card (E-ID) in Cimahi City, West Java Province, Indonesia," International Journal of Science and Research (IJSR), vol. 4, no. 2, pp. 31-41, 2015.

[4] Amin M. M., Sutrisman A., Stiawan D., Ermatita, and Maseleno A., "Design restful web service of national population database for supporting E-health interoperability service," Journal of Theoretical and Applied Information Technology, vol. 96, no. 15, pp. 4794-4805, 2018.

[5] Zeinali N., Asosheh A., and Setareh S., "The conceptual model to solve the problem of interoperability in health information systems," $20168^{\text {th }}$ International Symposium on Telecommunications (IST'2016), pp. 684-689, 2016.

[6] Suchaiya S. and Keretho S., "Analyzing national e-Government interoperability farmeworks: A case of Thailand," Ninth International Conference on Digital Information Management (ICDIM 2014), pp. 51-56, 2014.

[7] M. S. Hossain and M. Masud, "Medical data management and interoperability in e-health systems," 16th International Conference on Advanced Communication Technology, Pyeongchang, pp. 896-899, 2014.

[8] Geraci A., Katki F., McMonegal L., Meyer B., Lane J., Wilson P., Radatz J., Yee M., Porteous H., Springsteel F., "IEEE standard computer dictionary: compilation of IEEE standard computer glossaries," IEEE Press, 1991. 
[9] Wasala A., Buckley J., Schaler R., Exton C., "An empirical framework for evaluating interoperability of data exchange standards based on their actual usage: A case study on XLIFF," Computer Standards \& Interfaces, vol. 42, pp. 157-170, 2015

[10] M. Masud, M. S. Hossain and A. Alamri, "Data interoperability and multimedia content management in e-health Systems," in IEEE Transactions on Information Technology in Biomedicine, vol. 16, no. 6, pp. 1015-1023, Nov. 2012.

[11] Adebesin F., Foster R., Kotze P., Greunen D.V., "A review of interoperability standards in e-health and imperatives for their adoption in Africa," Research Article-SACJ, no. 50, pp. 55-72, 2013.

[12] Gaynor M., Yu F., Andrus C.H., Bradner S., and Rawn J., "A general framework for interoperability with applications to healthcare", Health Policy and Technology, vol. 3, pp. 3-12, 2014.

[13] Y. Guo, Y. Hu, J. Afzal and G. Bai, "Using P2P technology to achieve E-health interoperability," ICSSSM11, Tianjin, pp. 1-5, 2011

[14] Solanki M.R., Shah S., "A web service based design to integrate a web portal and an ERP system", International Journal of Engineering Research and Applications, vol. 4, no. 4, pp. 285-288, 2014.

[15] Erl T., "Service oriented architecture: concepts, technology, and design", Prentice Hall PTR, 2005.

[16] Kumari V., "Web services protocol: SOAP vs REST," International Journal of Advanced Research in Computer Engineering \& Technology (IJARCET), vol. 4, no. 5, pp. 2467-2469, 2015.

[17] Tihomirovs J., Grabis J., "Comparison of SOAP and REST based web services using software evaluation metrics," Information Technology and Management Science, vol. 19, pp. 92-97, 2016.

[18] Wagh K. and Thool R., "A comparative study of SOAP vs REST web services provisioning techniques for mobile host," Journal of Information Engineering and Applications, vol. 2, no. 2, pp. 12-16, 2012.

[19] Mumbaikar S., Padiya P., "Web services based on SOAP and REST principles," International Journal of Scientific and Research Publications, vol. 3, no. 5, pp. 1-4, 2013.

[20] Fielding, R. T., "Architectural styles and the design of network-based software architectures," (PhD thesis). University of California, Irvine, CA, 2000.

[21] Sinha R., Khatkar M., Gupta S. C., "Design \& Development of a REST based Web service platform for applications integration on cloud," International Journal of Innovative Science, Engineering \& Technology, vol. 1, no. 7, pp. 385-389, 2014.

[22] Sarno R., "Service-oriented analysis and design for project management applications," Penerbit Andi Offset Yogyakarta, 2012.

[23] Sarno R. and Herdiyanti A., "A service portfolio for an enterprise resource planning," International Journal of Computer Science and Network Security (IJCSNS), vol. 10, no. 3, pp. 144-156, 2010.

[24] Ziemann J., Matheis T., Freiheit J., "Modelling of cross-organizational business process," Enterprise Modelling and Information Systems Architectures, vol. 2, no. 2, pp. 23-31, 2017.

[25] R. Herkenhöner, H. de Meer, M. Jensen and H. C. Pöhls, "Towards automated processing of the right of access in inter-organizational web service compositions," 2010 6th World Congress on Services, Miami, FL, pp. 645-652, 2010. 